\title{
LENHOS DE CONÍFERAS DO MESOCRETÁCEO DO NORTE DO MARANHÃO, BRASIL
}

\author{
KIRLEY CRISTINA DE OLIVEIRAARAÚJO \\ Departamento de Biologia, UFMA, Av. dos Portugueses, s/n, 65085-580, São Luís, MA, Brasil. \\ kirleycristina-araujo@hotmail.com \\ MARGOT GUERRA SOMMER \\ Programa de Pós-Graduação em Geociências, UFRGS, Av. Bento Gonçalves, 9500, Cx.P. 15001, 91540-970, \\ Porto Alegre, RS, Brasil.margot.sommer@ufrgs.br \\ MANUEL ALFREDO MEDEIROS, EMÍLIA CRISTINA GIRNOS \\ Departamento de Biologia, UFMA, Av. dos Portugueses, s/n, 65085-580, São Luís, MA, Brasil.alf@ ufma.br \\ ISABELA DEGANI SCHMIDT \\ Programa de Pós-Graduação em Geociências, UFRGS, Av. Bento Gonçalves, 9500, Cx.P. 15001, 91540-970, \\ Porto Alegre, RS, Brasil.degani.schmidt@ufrgs.br
}

\begin{abstract}
CONIFER WOODS FROM THE MIDDLE CRETACEOUS OF NORTHERN MARANHÃO STATE, BRAZIL. In the present work, 13 silicified logs collected in the fossiliferous levels of the Alcântara Formation (Upper AlbianLower Cenomanian estuarine deposits in northern Maranhão State, NE Brazil) were analyzed through petrographic slides applying parataxonomic approach. The gymnospermous araucarioid pattern is the prevailing pattern observed in the wood association, suggesting a possible relation to the Araucariaceae. Considering that pollen grains of Araucariacites australis were previously reported from the same sedimentary deposits where the sample came from, the presence of Araucariacea is assumed, mainly in the estuarine environment inferred for the region of Alcântara and São Luís. Conifers with abietoid wood pattern may be related to Taxaceae and probably throve in inland areas. The absence of angiospermous woods in the assemblage, opposed to the expressive representation in palynological analyses, can be attributed to a combination of taphonomic factors or, alternatively, to the development of conifer and angiosperm plants in distinct paleoenvironment during the middle Creataceous. The predominance of uninterrupted wood growth and rare evidences of partially interrupted wood growth patterns and the presence of radial desiccation cracks led to the inference of a stable paleoclimate, but with sporadic drought episodes during growing season, included in global scale in the equatorial humid belt in the boundary with the northern hot arid belt.
\end{abstract}

Key words: xylotypes, araucarioid, abietoid, Alcântara Formation, Upper Albian-Lower Cenomanian.

\begin{abstract}
RESUMO - No presente trabalho, 13 fragmentos de lenhos silicificados coletados nos níveis fossilíferos da Formação Alcântara (Albiano superior-Cenomaniano inferior do norte do Estado do Maranhão, NE Brasil) foram estudados a partir da análise de lâminas petrográficas, utilizando critérios parataxonômicos. O padrão gimnospérmico é exclusivo nas amostras, com dominância de xilema de coníferas de tipo araucarioide, sugerindo, de forma ampla, uma possível relação com a família Araucariaceae. Considerando que Araucariacites australis é um grão de pólen abundantemente reportado nesses mesmos depósitos sedimentares de onde provém a amostra, a presença de Araucariaceae é assumida no ambiente estuarino que existiu na região de Alcântara e São Luís. Coníferas representadas por formas com padrão abietóide, talvez relacionado à Taxaceae, medravam provavelmente em áreas mais interiores. A ausência de lenho de Angiospermae, que se contrapõe à sua expressiva diversidade nos registros fósseis palinológicos, é atribuída a uma combinação de circunstâncias tafonômicas ou, alternativamente, ao desenvolvimento de coníferas e angiospermas em paleoambientes diferenciados no intervalo estudado. A dominância de padrões de crescimento ininterrupto do lenho, com registro de padrões de crescimento parcialmente interrompido em raros espécimes, associado à presença de lacunas de ressecamento no xilema, levou à inferência de um paleoclima estável com ocorrência esporádica de secas na fase de crescimento, incluído em escala global no cinturão equatorial úmido na área limítrofe com o cinturão quente e árido do Norte.
\end{abstract}

Palavras-chave: xilotipos, araucarioide, abietoide, Formação Alcântara, Albiano superior-Cenomaniano inferior.

\section{INTRODUÇÃO}

No norte do Estado do Maranhão, nordeste do Brasil, rochas cretáceas afloram nas falésias litorâneas revelando uma associação de fácies sedimentares depositadas por um sistema estuarino datado como Eocenomaniano. Todo o conjunto pós-Aptiano do norte maranhense originalmente era incluído na então chamada Formação Itapecuru, mas posteriormente essa designação passou a definir um grupo de formações (Grupo Itapecuru) e as rochas aflorantes nas praias 
de São Luís e Alcântara passaram a compor a Formação Alcântara (Campbell et al., 1949; Mesner \& Wooldridge, 1964; Aranha et al., 1990; Pedrão et al., 1993a,b,c; Rossetti \& Truckenbrodt, 1997).

Os horizontes aflorantes na Ilha do Cajual, dentro do território de Alcântara, incluem arenitos estratificados formados em um delta de maré e pelitos e arenitos rítmicos resultantes do preenchimento de uma baía de maré. Conglomerados fossilíferos ocorrem na base dos arenitos estratificados e são interpretados como resultantes de um episódio de subida do nível do mar, tendo reunido fósseis de vertebrados e vegetais retrabalhados de depósitos continentais pré-existentes (Holz, 2003). A idade dos fósseis é estimada como albiana-eocenomaniana (Pedrão et al., 1993c; Medeiros, 2001), e a tafocenose do nível sedimentar chamado Laje do Coringa é a mais expressiva de todo o norte maranhense, reunindo milhares de exemplares fósseis de vertebrados e vegetais (Corrêa Martins, 1997; Medeiros, 2001).

O presente trabalho objetiva (i) estabelecer a análise anatômica de uma amostra de lenhos silicificados oriundos da Laje do Coringa com intuito de reconhecer a composição da paleoflora do norte maranhense no Neoalbiano/ Eocenomaniano, e (ii) contextualizar os resultados nos âmbitos paleoclimático, paleoecológico e paleobiogeográfico.

\section{CONTEXTO GEOLÓGICO}

\section{Bacia de São Luís-Grajaú e o registro Cretáceo no Maranhão}

No Período Cretáceo, a configuração continental modificouse profundamente desde um padrão constituído por Laurásia e Gondwana (Gradstein \& Ogg, 1996; Smit, 1999; Skelton et al., 2003) até um multicontinental, que definiria posteriormente a configuração atual das terras emersas (Skelton et al., 2003). Durante a franca separação da América do Sul da África, tectonismos extensionais ocorreram ao longo da fratura que viria a originar a costa norte e leste do Brasil, formando falhas, grabens e horsts. A bacia de São Luis-Grajaú (Figura 1) originou-se do graben do Gurupi e inclui todo o norte do Estado do Maranhão (Rossetti, 2001; Góes \& Rossetti, 2001).

A bacia de São Luís-Grajaú contém alguns dos principais registros fósseis e geológicos do Cretáceo brasileiro, em depósitos do Aptiano ao Cenomaniano (ver revisão e sumarização em Rossetti et al., 2001a). Os depósitos fossilíferos mais expressivos ocorrem ao longo do vale do rio Itapecuru, nos municípios de Codó, Coroatá e Itapecuru Mirim e nas falésias litorâneas de Alcântara e São Luís, no Golfão Maranhense (Figura 1).

\section{Formação Alcântara: paleoambiente e registro fóssil}

De idade neoalbiana/eocenomaniana, a Formação Alcântara aflora extensivamente na porção norte da bacia de São Luís-Grajaú. Consiste em arenitos, argilitos e calcários atribuídos a ambientes de shoreface médio a superior, foreshore, canal de maré, laguna e delta de washover, contextualizando um sistema de ilhas barreiras. Sua variedade de feições sedimentares é consistente com significante afluxo de água doce dentro de um ambiente lagunar com conexão estuarina (Rossetti, 1997; Rossetti \& Truckenbrodt, 1997). O abundante registro fóssil desta formação revelou uma paleofauna muito assemelhada àquela documentada nos depósitos cronocorrelatos continentais do norte africano, incluindo dinossauros, crocodilos, pterossauros, peixes e vegetais fósseis como pteridófitas arborescentes e lenhos de coníferas (Corrêa Martins, 1997; Medeiros, 2001; Medeiros \& Schultz, 2002, 2004; Elias et al., 2007; Pereira \& Medeiros, 2008). A paleoflora, todavia, é pouco conhecida, sendo a pteridófita arborescente Paradoxopteris sanctiluigi Mussa et al., 2000 o único táxon descrito.

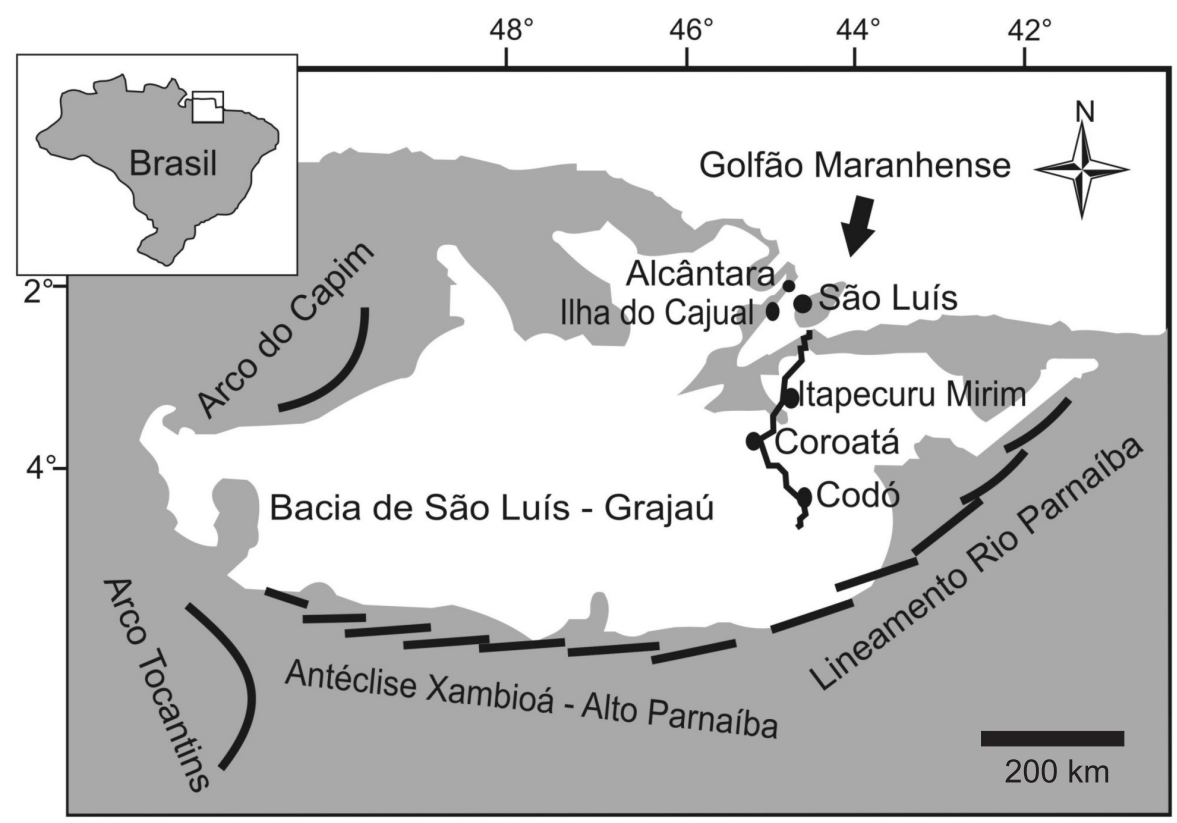

Figura 1. Mapa de localização da bacia de São Luís-Grajaú, mostrando seus limites e a amplitude das rochas cretáceas (área em branco). Os principais horizontes fossilíferos afloram no vale do rio Itapecuru e no Golfão Maranhense (baseado em Rossetti, 2001).

Figure 1. Location map showing the limits and the range of the Cretaceous rocks in the São Luís-Grajaú Basin (white area). The main fossiliferous levels outcrop at the valley of the Itapecuru River and in the Maranhense Gulf (after Rossetti, 2001). 


\section{MATERIAL E MÉTODOS}

O material estudado compreende 13 fragmentos de lenhos fósseis, coletados aleatoriamente no afloramento Laje do Coringa, Ilha do Cajual, Neoalbiano/Eocenomaniano da Formação Alcântara, bacia de São Luís-Grajaú. Os espécimes são silicificados (permineralização celular $c f$. Schopf, 1975) e fragmentados, restringindo-se a porções do xilema secundário, medindo de 8,5 a $40 \mathrm{~cm}$ de comprimento com diâmetro de 2 a $19 \mathrm{~cm}$. Os espécimes estão tombados na coleção paleontológica do Departamento de Biologia da Universidade Federal do Maranhão (UFMA), em São Luís, sob os números: UFMA 2.10.015, UFMA 2.10.017,UFMA2.10.019,UFMA2.10.021,UFMA2.10.023,UFMA 2.10.029, UFMA2.10.050,UFMA2.10.056,UFMA2.10.122,UFMA 2.10.126,UFMA2.10.194,UFMA2.10.196eUFMA2.10.199.

\section{Técnicas de preparação}

Foram efetuadas seções planas e lâminas delgadas com a finalidade de caracterizar as estruturas anatômicas e identificar os padrões de crescimento. Os cortes foram realizados no Laboratório de Laminação do Departamento de Mineralogia e Petrologia, Instituto de Geociências da Universidade Federal do Rio Grande do Sul e no Laboratório de Preparação de Lâminas Petrográficas da UNISINOS, São Leopoldo, RS. Foram executadas duas lâminas para cada um dos três planos anatômicos (transversal, radial e tangencial) em cada um dos 13 espécimes, seguindo nessa análise os padrões estabelecidos para madeiras atuais. $\mathrm{O}$ desgaste foi controlado microscopicamente em cada lâmina até obter espessuras que permitissem a visualização das diferentes estruturas anatômicas.

Foram efetuadas 50 medições em cada espécime para estabelecer o padrão vigorante nas diferentes estruturas, porém para os campos de cruzamento foram efetuadas 15 medições por espécime, pois o estágio de preservação era mais precário. A contagem dos raios lenhosos foi efetuada utilizando-se padrões de frequência por mm linear. Foram para tanto contados raios ocorrentes em $3 \mathrm{~mm}$ lineares em cada lâmina tangencial.

\section{Registro fotográfico}

Os lenhos fósseis, as seções planas e as lâminas delgadas foram fotografados no Instituto de Geociências, Depar- tamento de Paleontologia e Estratigrafia da Universidade Federal do Rio Grande do Sul, com máquina fotográfica digital Sony Cyber Shot DSC-W5 e as fotos armazenadas digitalmente. Fotos das lâminas nas três seções foram obtidas com sistema automático de fotografias acoplado a microscópio óptico de luz transmitida Carl Zeiss, MC80 e filmes coloridos Kodak T-Max 100 e reveladas em papel opaco.

\section{Técnicas de análise}

Utilizou-se sistemática parataxonômica definida a partir da caracterização de tipos de lenho (xilotipos), semelhante à adotada para folhas cretáceas (Johnson, 1996) como também para lenhos do Paleoceno da bacia de Denver e em associações de lenhos do intervalo Cretáceo-Paleoceno do Big Bend National Park, Texas (Wheeler \& Michalsky, 2003; Wheeler \& Lehman, 2005). Esses estudos foram elaborados com base no método definido por Page $(1979,1980,1981)$.

A caracterização do crescimento arbóreo foi estabelecida a partir das definições de Schweingruber (1996), Creber \& Francis (1999) e Creber \& Chaloner (1984). A ausência de verdadeiros anéis de crescimento impediu a obtenção de medidas de sensibilidade média e de sensibilidade anual, conforme critérios de Creber \& Chaloner (1984).

\section{RESULTADOS}

A superfície dos espécimes é, de modo geral, irregular, ocorrendo, em sua maioria, arestas bem definidas (Figura 2A) e, em raras formas, arredondamento de arestas (Figuras 2B,C). Frequentemente ocorrem ostras recentes aderidas à superfície externa (Figura 2C), visto que o material foi coletado em ambiente de praia. Em poucos fragmentos, em seções transversais, percebe-se ocorrência de bandas que sugerem ciclicidade no padrão de crescimento (Figura 2D), evidência essa confirmada nos estudos anatômicos.

A partir de análise anatômica desse material foram caracterizados dois padrões de lenhos cujas distinções morfológicas são descritas a seguir e sumarizadas na Tabela 1.

\section{Xilotipo araucarioide}

Espécimes. UFMA 2.10.015; UFMA 2.10.017; UFMA 2.10.019;

Tabela 1. Padrões anatômicos dos xilotipos araucarioide e abietoide.

Table 1. Anatomic patterns of araucarioid and abietoid xylotypes.

\begin{tabular}{|c|c|c|c|}
\hline & S eção trans versal & Seção radial & Seção tangencial \\
\hline $\begin{array}{l}\text { Xilotipo } \\
\text { araucarioide }\end{array}$ & $\begin{array}{l}\text { Traqueídeos com contorno } \\
\text { angular a arredondado; } \\
\text { parênquima axial presente; } \\
\text { padrões de crescimento } \\
\text { ininterrupto ou parcialmente } \\
\text { interrompido evidenciados } \\
\text { por zonas de crescimento. }\end{array}$ & $\begin{array}{l}\text { Paredes dos traqueídeos com } \\
\text { pontoações areoladas alternas } \\
\text { bisseriadas ( } 85 \%) \text {, trisseriadas (15\%) } \\
\text { e unisseriadas contíguas }(5 \%) \text {; poro } \\
\text { central redondo a oval; campos de } \\
\text { cruzamento apresentando oculiporos } \\
\text { (1-6) cupres sóides em arranjo } \\
\text { araucarióide. }\end{array}$ & $\begin{array}{l}\text { Ausência de pontoações e } \\
\text { ausência de reforços espiralados } \\
\text { nas paredes dos traqueídeos; raios } \\
\text { lenhosos unis seriados ou } \\
\text { parcialmente bisseriados (raros), } \\
\text { duas a oito células, mistos, com } \\
\text { células resiníferas; parênquima } \\
\text { axial presente. }\end{array}$ \\
\hline $\begin{array}{l}\text { Xilotipo } \\
\text { abietoide }\end{array}$ & $\begin{array}{l}\text { Traqueídeos com contorno } \\
\text { arredondado; parênquima } \\
\text { axial presente; padrão de } \\
\text { crescimento ininterrupto. }\end{array}$ & $\begin{array}{l}\text { Paredes dos traqueídeos com } \\
\text { pontoações areoladas circulares } \\
\text { isoladas, raro contíguas; poro central } \\
\text { arredondado; reforços espiralados em } \\
\text { ângulo de } 50^{\circ} \text {; campos de cruzamento } \\
\text { apresentando ooporos simples, } \\
\text { únicos, podocarpóides. }\end{array}$ & $\begin{array}{l}\text { Ausência de pontoações e } \\
\text { presença de reforços espiralados } \\
\text { em ângulo de } 50^{\circ} \text { nas paredes dos } \\
\text { traqueídeos; raios lenhosos } \\
\text { unisseriados baixos, uma a cinco } \\
\text { células; parênquima axial } \\
\text { presente. }\end{array}$ \\
\hline
\end{tabular}


UFMA 2.10.021; UFMA 2.10.023; UFMA 2.10.029; UFMA 2.10.056; UFMA 2.10.122; UFMA 2.10.126; UFMA 2.10.194. UFMA 2.10.196; UFMA 2.10.199.

Descrição. Lenho de padrão homoxílico gimnospérmico. Traqueídeos de contorno angular a arredondado com diâmetro radial no lenho inicial médio de $60 \mu \mathrm{m}$ e de $38 \mu \mathrm{m}$ no lenho final. Pontoações radiais areoladas, em sua maioria bisseriada alterna $(85 \%)$, às vezes trisseriada alterna $(10 \%) \mathrm{e}$, mais raramente, unisseriadas contíguas (5\%) (Figuras 3 A-C). Poro central arredondado, às vezes (30\%) ligeiramente ovalado e com variação na disposição no traqueídeo. Pontoações unisseriadas circulares achatadas (diâmetro de 24 a 60 m). Pontoações alternas bisseriadas semi-poligonais e trisseriadas francamente poligonais. Campos de cruzamento com pontoações tipo oculiporo (diâmetro médio de $6 \mu \mathrm{m}$ ), cupressoides, em número de 1 até 6 (30\%), sem orientação definida (Figura 3D). Quando muito numerosas (5 a 6), as pontoações são semicirculares a semi-poligonais. Predomínio de raios unisseriados $(90 \%)$ e, muito raramente parcialmente bisseriados (Figura 3E). Raios com duas a seis (40\%) células de altura (até $70 \mu \mathrm{m}$ ), em uma densidade média de 13/ mm linear. Ocorrência de células, associadas aos raios, com conteúdo escuro, provavelmente resinífero (Figura 3E). Raios com terminalizações agudas, raramente encurvadas.

Discussão. Na grande maioria dos espécimes não são detectadas alterações de diâmetro radial e tangencial dos traqueídeos ao longo de toda a superfície transversal e, consequentemente, evidencia-se a ausência de zonas de crescimento ou anéis de crescimento (Figura 4A). Em dois espécimes (UFMA 2.10.029e UFMA 2.10.199), porém, ocorrem zonas de crescimento, detectadas em intervalos máximos de $5 \mathrm{~mm}$ (Figura 4B). Essas zonas, que caracterizam padrão de crescimento parcialmente interrompido são representadas anatomicamente por uma fase onde se evidencia a redução do lúmen dos traqueídeos, sem correspondente aumento de espessura da parede, seguida por outra fase que se caracteriza pelo gradacional aumento do diâmetro do lúmen, sem que, contudo, se caracterize uma linha nítida de interrupção do crescimento, como nos típicos anéis de crescimento. A espessura de parede dos traqueídeos de lenho inicial e de lenho final não varia. Constitui-se em característica comum nos lenhos aqui estudados a presença, em áreas bem definidas do xilema, de células preenchidas por substância escura que ocorrem em disposição axial dispersas no xilema secundário (Figuras $3 \mathrm{E}, 4 \mathrm{~B}$ ) que podem corresponder a traqueídeos resiníferos ou a parênquima axial. Em um dos espécimes observou-se, em seção transversal, linhas geradas por escalonamento, que não representam alteração de padrão de crescimento (Figura 5A).

Evidências de disrupções no crescimento do lenho são representadas na amostra, em seção transversal, por fraturas com orientação radial (comprimento de 1 a 4 mm, largura máxima de $1 \mathrm{~mm}$ ), nas quais ocorre ruptura ao longo das fileiras de traqueídeos. Essas fraturas são preenchidas por sílica e não se observam em seu interior restos orgânicos dispersos e gênese de tecido de tipo callus (Figura 5B). A degradação do lenho por fungos é registrada na amostra através de diferentes evidências, tais como hifas e esporos no lúmen celular e dispersos (Figura 5C), além de alterações da parede celular (Figura 5D). A análise detalhada desse material é escopo de trabalho em elaboração.

O padrão xilemático ilustrado na Figura 3 caracteriza lenhos anteriormente atribuídos ao morfogênero Araucarioxylon Kraus, típico de floras mesozoicas gondwânicas. Estudos de anatomia

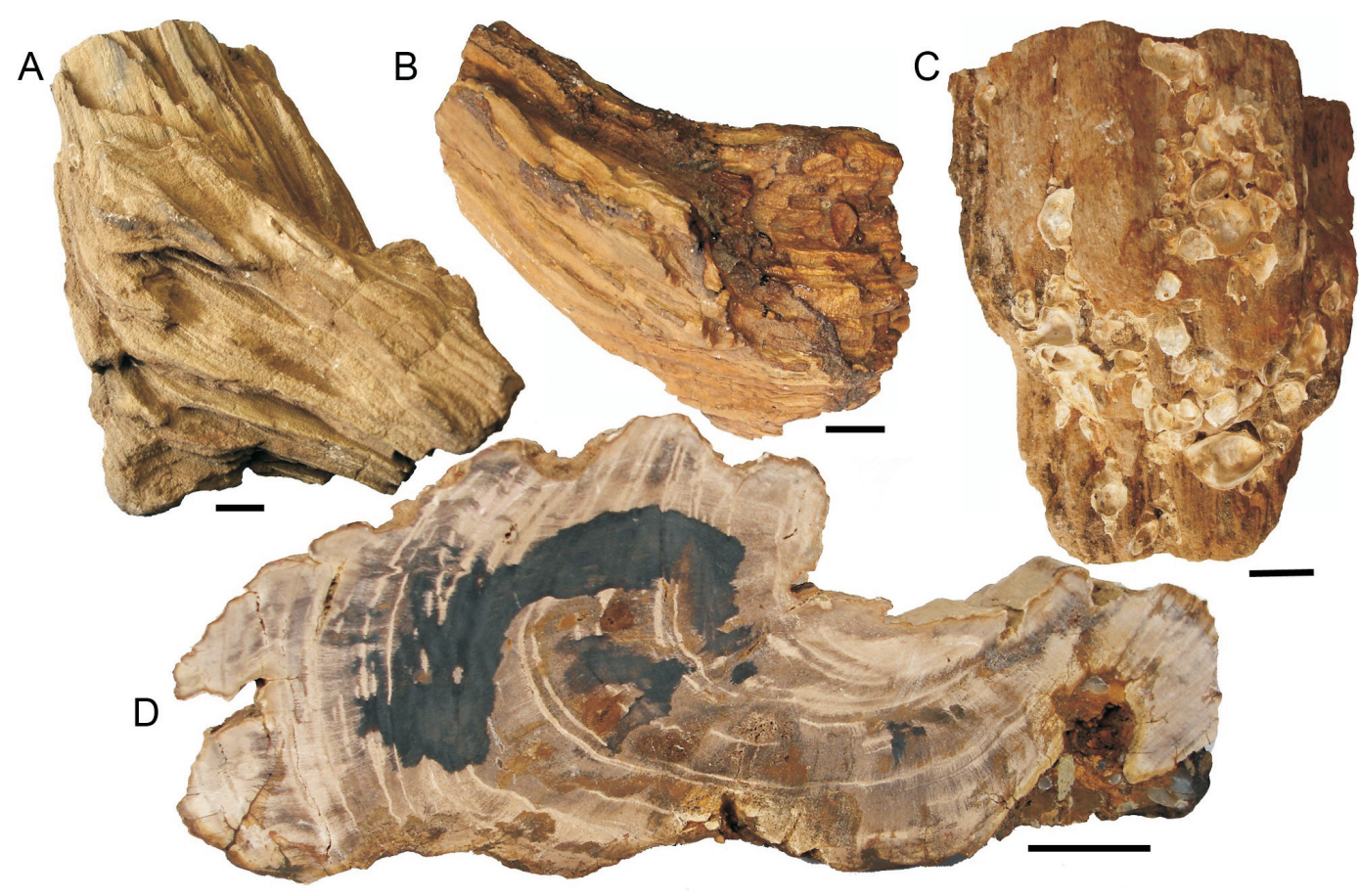

Figura 2. Fragmentos de lenhos em observação mesoscópica. Vista lateral: A, espécime com pouco desgaste (UFMA 2.10.029); B, matriz do conglomerado aderida à superfície externa do espécime (UFMA 2.10.066); C, espécime com desgaste apresentando arestas atenuadas e conchas de ostra (UFMA 2.10.017); D, seção transversal de espécime com zonas de crescimento (UFMA 2.10.123). Escalas = $2 \mathrm{~cm}$.

Figure 2. Mesoscopic view of wood fragments. Side view: A, little abraded specimen (UFMA 2.10.029); B, conglomeratic matrix adhered to the external surface of the specimen (UFMA 2.10.066); C, specimen with rounded edges and oyster shells on the surface (UFMA 2.10.017); D, cross section of specimen with growth zones (UFMA 2.10.123). Scale bars $=2 \mathrm{~cm}$. 
ontogenética em Araucariaceae (Boureau, 1956) demonstraram que Araucarioxylon representa táxon coletivo que inclui formas filogeneticamente muito distintas. Concordantemente com o que estabelece Philippe (1993), Philippe \& Bamford (2008) consideram Araucarioxylon como gênero inválido e as formas anteriormente a ele referidas passam a ser incluídas em Agathoxylon (Harting).

A presença de células axiais preenchidas por substância escura, provavelmente resinífera, representaria para Boureau (1956) processos evolutivos gerados ao longo do Mesozoico nos elementos condutores do xilema secundário que culminariam na geração de parênquima axial em formas mais modernas. Essas substâncias preenchem também células de raios. Por outro lado, esse tipo de estruturação é semelhante ao encontrado em coníferas atuais como resultado da concentração de resinas nos raios e em traqueídeos em resposta a processos de indução de caráter ambiental. Levando em consideração a pequena amostragem e o estágio precário de preservação da maioria dos espécimes, é prematuro optar por uma dessas hipóteses, pois tem sido atribuído caráter taxonômico a essas estruturas resiníferas ou então relação com respostas a injúrias ao desenvolvimento do lenho (Schweingruber, 2007). Essa incerteza impede uma identificação do padrão descrito com o morfogênero Agathoxylon.
Diversos xilotipos araucarioides foram registrados por Wheeler \& Lehman (2005) ao estabelecerem características diferenciais entre lenhos de coníferas procedentes do Cretáceo Superior do Big Bend National Park, Texas. Os padrões de lenho definidos através de xilotipos são parataxonômicos e, portanto, não ensejam uma correlação segura com grupos vegetais estabelecidos a partir da sistemática natural. Desse modo, a parataxonomia deve se restringir a termos descritivos, evitando inferências etimológicas. Mesmo com essas restrições, Wheeler \& Lehman (2005) estabelecem prováveis afinidades entre os tipos xilemáticos araucarioides com a família Araucariaceae ou com a família extinta Cheirolepidiaceae que se desenvolveu no intervalo Triássico-Neocretáceo/Terciário. Essas inferências têm como suporte a presença de grãos de pólen de ambas as famílias procedentes dos sedimentos de onde foram coletados os lenhos. Todavia, análises de padrões xilemáticos relacionados à Cheirolepidiaceae têm relacionado a esse grupo os morfogêneros Protocupressinoxylon Eckhold, Brachyoxylon Hollick \& Geffrey e, principalmente, Protopodocarpoxylon Eckhold, cujas características anatômicas distinguem-nos dos morfogêneros mais afins a Araucariaceae (Lauverjat \& Pons, 1978; Alvin et al., 1981; Alvin, 1982; Axsmith, 2006).

$\mathrm{O}$ estabelecimento de afinidades, ainda que generalizadamente, entre o material procedente da Laje do
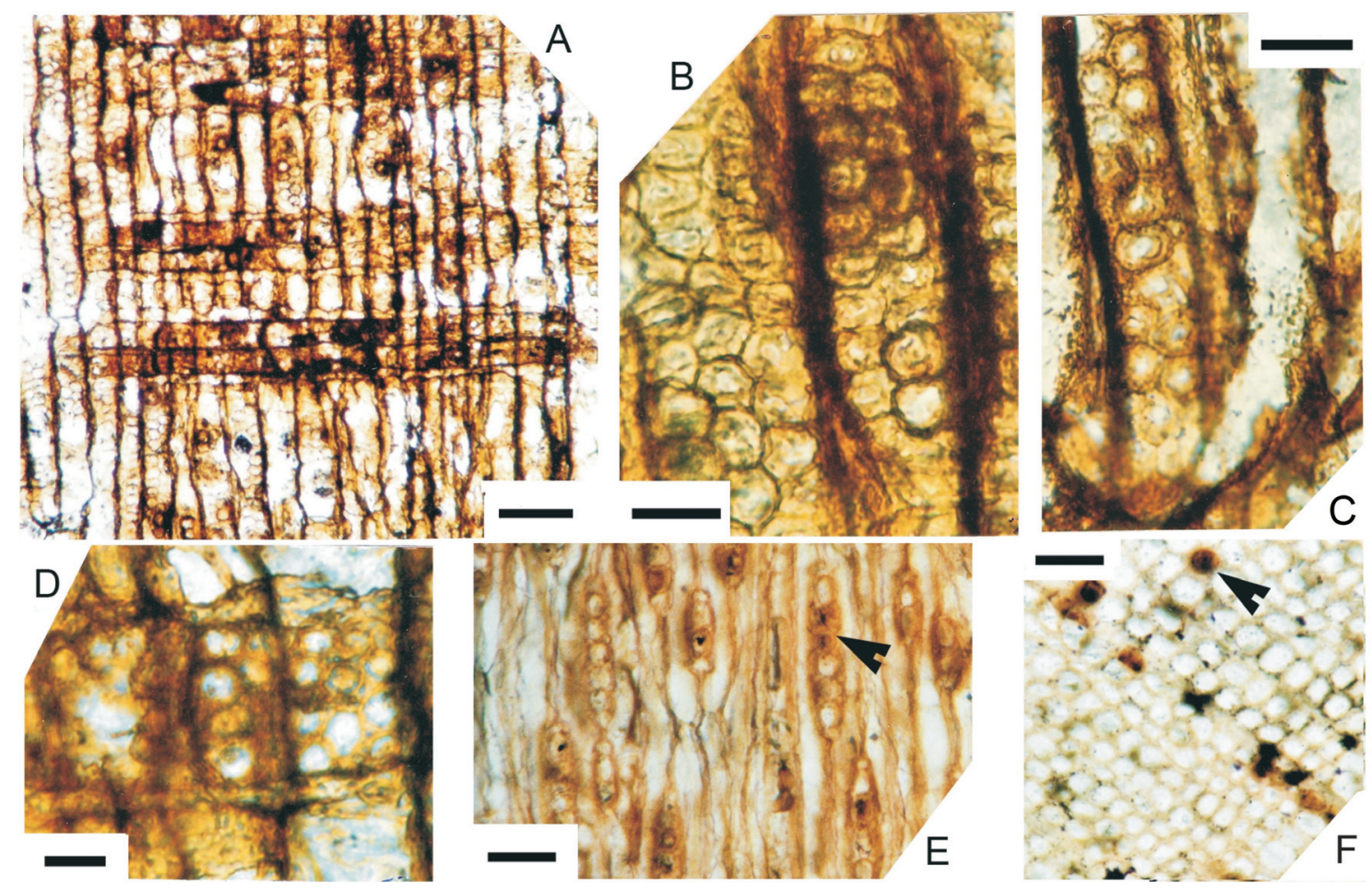

Figura 3. Xilotipo araucarioide (UFMA 2.10.019). Seção radial: A, vista geral; B, traqueídeos com pontoações areoladas trisseriadas alternas poligonais com poro circular a oval, pontoações alternas com disposição bisseriada em traqueídeo contíguo; C, pontoações areoladas com disposição em um mesmo traqueídeo variando de unisseriada a bisseriada alterna; $\mathbf{D}$, campos de cruzamento com pontoações cupressoides, oculiporos e contorno circular quando isolada e poligonal quando comprimida. Seção tangencial: E (UFMA 2.10.015), raio unisseriados e raramente bisseriados e algumas células de raio com inclusões escuras (seta). Seção tranversal: $\mathbf{F}$ (UFMA 2.10.015), traqueídeos com contorno angular a arredondado e células com inclusões escuras (seta). Escalas: A, E, F = 26,6 $\mu \mathrm{m} ; \mathrm{B}, \mathrm{D}=12,8 \mu \mathrm{m}$.

Figure 3. Araucarioid xylotype (UFMA 2.10.019). Radial section: A, general view; B, bordered pits of the tracheids, in triseriate alternate disposition, polygonal shaped, showing rounded to oval central pore and adjacent tracheid with biseriate bordered pits in alternate disposition; C, bordered pits changing from uniseriate to biseriate alternate disposition in the same tracheid; $\mathbf{D}$, cross field pits oculipore, cupressoid, circular when isolated and polygonal when compressed. Tangential section: E (UFMA 2.10.015), prevailing uniseriate and rare biseriate rays and cells with dark inclusions (arrow). Cross section: F (UFMA 2.10.015), square to round shaped tracheids and cells with dark inclusions (arrow). Scale bars: A, E, $F=26,6 \mu \mathrm{m} ; \mathrm{B}, \mathrm{D}=12,8 \mu \mathrm{m}$. 
Coringa (Formação Alcântara) e determinados grupos de coníferas, possibilita uma correlação com a família Araucariaceae e com o gênero Araucaria L. Jussieu dado as disposições unia trisseriadas alternas das pontoações radiais dos traqueídeos. Todavia, a presença de parênquima axial no material estudado tem sido referida apenas no gênero Agathis Panch e a disposição das pontoações nos campos de cruzamento em Agathis também é muito semelhante ao material estudado (Boureau, 1956).
Da mesma forma que ocorre na sequência estratigráfica estudada por Wheeler \& Lehman (2005), grãos de pólen de Araucariaceae (Araucariacites australis Cookson) e Cheirolepidiaceae (Classopollis sp. Regali, Uesugui \& Lima) foram registrados por Pedrão et al. (1993a,b,c) e Rossetti et al. (2001b) para sedimentos cretáceos da bacia de São Luís-Grajaú. Todavia, os dados anatômicos disponíveis indicam uma correlação com padrões de lenhos que se vinculam a Araucariaceae.

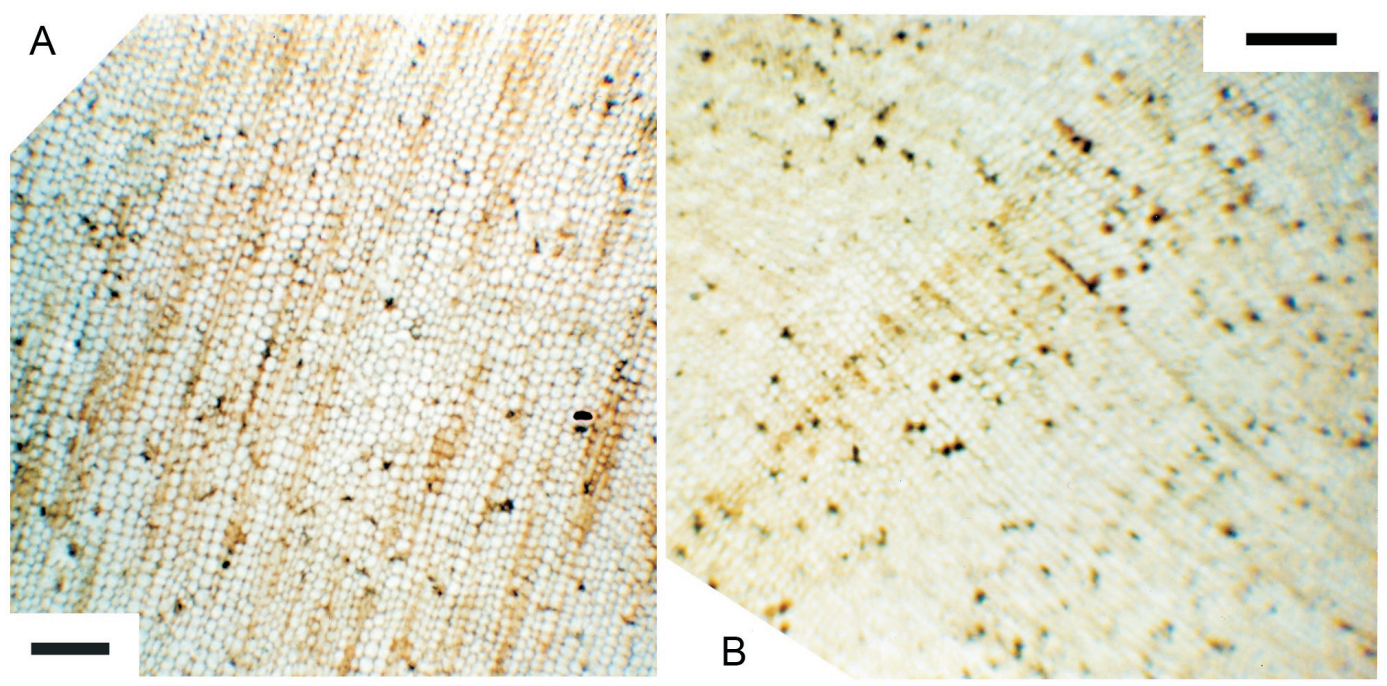

Figura 4. Seções transversais mostrando o padrão de crescimento. A (UFMA 2.10.023), padrão ininterrupto; B (UFMA 2.10.015), padrão parcialmente interrompido; zona de crescimento com células ligeiramente angulosas e maior diâmetro dos lúmens celulares. Escalas $=64 \mu \mathrm{m}$.

Figure 4. Growth patterns in cross view. A (UFMA 2.10.023), uninterrupted growth pattern; B (UFMA 2.10.015), partially uninterrupted growth pattern, growth zone with slightly angular cells and larger lumen diameter. Scale bars $=64 \mu \mathrm{m}$.

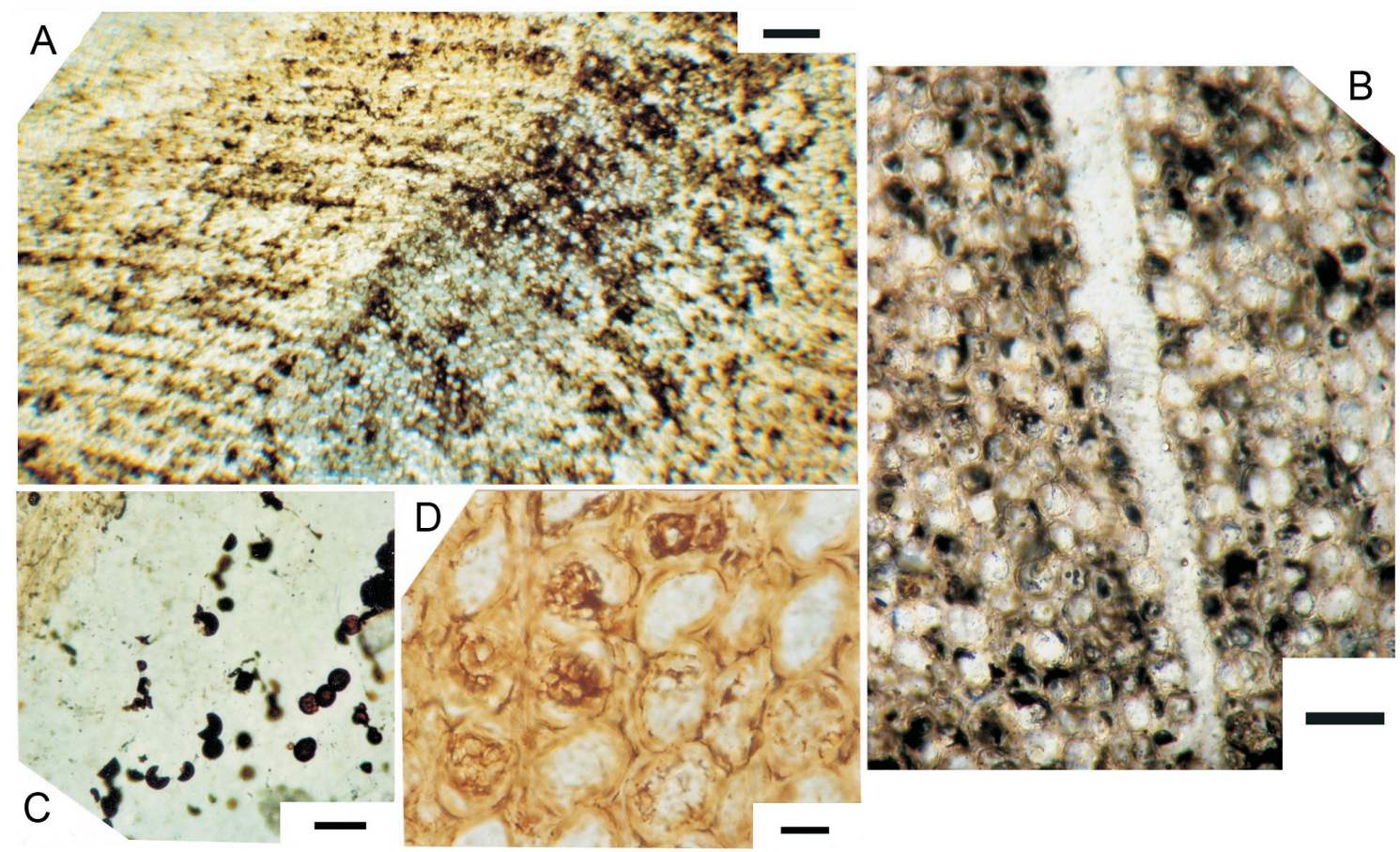

Figura 5. A (UFMA 2.10.126), seção transversal mostrando compressão do xilema secundário; B (UFMA 2.10.050), fratura radial preenchida; C (UFMA 2.10.126), esporos de fungos; D (UFMA 2.10.023), clamidósporos e degradação da parede celular. Escalas: $A=64$ $\mu \mathrm{m} ; \mathrm{B}, \mathrm{C}=26,6 \mu \mathrm{m} ; \mathrm{D}=12,8 \mu \mathrm{m}$.

Figure 5. A (UFMA 2.10.126), cross section showing compressed secondary wood; B (UFMA 2.10.050), filled radial crack; C (UFMA 2.10.126), fungal spores; D (UFMA 2.10.023), chlamydospores and degradation of cell wall. Scale bars: $A=64 \mu \mathrm{m} ; B, C=26,6 \mu \mathrm{m} ; \mathrm{D}=12,8 \mu \mathrm{m}$. 


\section{Xilotipo abietoide}

Espécime. UFMA 2.10.050

Descrição. Traqueídeos de contorno angular com diâmetro radial de $40 \mathrm{~cm}$. Presença em sessão radial e tangencial de espessamentos espiralados com ângulo médio de $50^{\circ}$ (Figuras 6A-B), pontoações unisseriadas predominantemente isoladas (90\%) e, muito raramente, contíguas (Figura 6A) com poro central circular. Campos de cruzamento mal preservados, mas com pontoações de tipo ooporo grandes (10 $\mu \mathrm{m}$ de diâmetro), simples, únicas ou esporadicamente duplas por campo (Figura 6C), semelhantes ao tipo podocarpoide. O padrão de crescimento é ininterrupto, caracterizando-se pela ausência de zonas de crescimento ou anéis de crescimento.

Raios unisseriados com até cinco células de altura (Figura 6D) com densidade de $23 / \mathrm{mm}$ linear. Células com orientação axial e septadas, provavelmente de parênquima axial, evidenciadas nas seções tangenciais (Figura 6E). Nessa seção ficam comprovados os espessamentos espiralados nas paredes dos traqueídeos que aparecem aqui como estruturas cruzadas, aparentando um retículo (Figura 6F).

Discussão. Esse padrão anatômico é registrado apenas no espécime UFMA 2.10.050, mas possui características diagnósticas marcantemente distintas em relação ao morfotipo araucarioide. A presença de reforços espirais nas paredes dos traqueídeos constitui uma importante característica na distinção morfotípica de coníferas mesozoicas. Esses espessamentos espirais distinguem-se daqueles que se originam como consequência da for- mação de lenhos de tensão em coníferas, os quais têm sido relatados em lenhos atuais e fósseis. Estes têm ângulo de inserção na parede longitudinal do traqueídeo muito mais oblíquo do que em verdadeiros reforços espirais. A disposição cruzada, aparentando falsos retículos em vista tangencial, confirma sua afinidade com verdadeiros reforços que são registrados atualmente em alguns gêneros de coníferas nas famílias Taxaceae, Cupressaceae e Pinaceae (Boureau, 1956).

Em lenhos fósseis mesozoicos, a presença de reforços espiralados nas paredes secundárias dos traqueídeos tem sido registrada em diferentes espécies do morfogênero Prototaxoxylon Krausel \& Dolianiti, que corresponde a um morfogênero erigido a partir de fragmentos de xilema secundário, incluído no grupo artificial Protopinaceae que sinonimiza espécies anteriormente referidas a Spiroxylon Walton non Hartig (Philippe \& Bamford, 2008). Inclui todos os lenhos com espessamentos espiralados nos traqueídeos e pontoações areoladas unisseriadas contíguas ou bisseriadas alternas. Esse lenho distingue-se do material estudado por apresentar pontoações radiais de tipo araucarioide e, nos campos de cruzamento, oculiporos cupressoides ou taxodioides. Espirais nas paredes dos traqueídeos são referidos para Platispiroxylon Greguss. Todavia, Philippe \& Bamford (2008) afirmam que as supostas espirais são efeitos de alteração do lenho e que tal morfogênero não deve ser utilizado.

A presença de pontoações unisseriadas predominantemente isoladas na parede radial dos traqueídeos, de tipo abietoide,
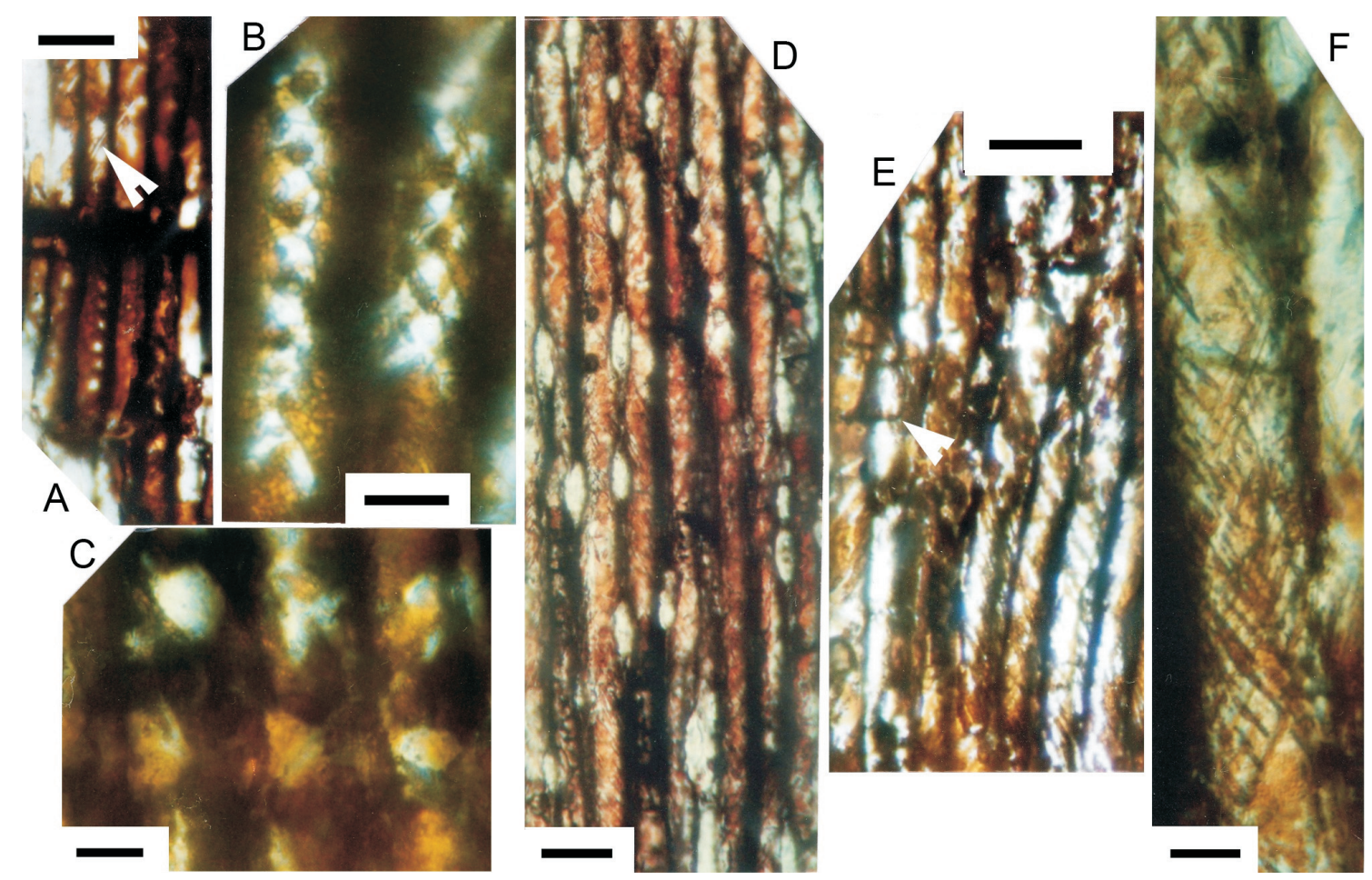

Figura 6. Xilotipo abietoide (UFMA 2.10. 050). Seção radial: A, pontoações unisseriadas espaçadas nas paredes dos traqueídeos e espessamentos espiralados (seta); B,espessamentos espiralados e pontoações unisseriadas areoladas circulares com poro central circular; C, campos de cruzamento ostentando ooporos simples, de tipo podocarpóide. Seção tangencial: D, raios lenhosos unisseriados com poucas células de altura; $\mathbf{E}$, traqueídeos com espessamentos espiralados, células septadas (seta); $\mathbf{F}$, detalhe dos espessamentos espiralados. Escalas: A, D, E = 26,6 $\mu \mathrm{m} ; \mathrm{B}, \mathrm{C}, \mathrm{F}=12,8 \mu \mathrm{m}$.

Figure 6. Abietoid xylotype (UFMA 2.10. 050). Radial section: A, uniseriate, isolated bordered pits and spiral thickening (arrow) in tracheids; B, spiral thickening and uniseriate, isolated bordered pits with rounded central pore; C, cross field oopores of podocarpoid type. Tangential section: D, short uniseriate rays; $\mathbf{E}$, spiral thickening in tracheid wall, septate cells (arrow); $\mathbf{F}$, detail of spiral thickening. Scale bars: $A, D, E=26,6 \mu \mathrm{m} ; \mathrm{B}, \mathrm{C}, \mathrm{F}=12,8 \mu \mathrm{m}$. 
portanto, associadas a reforços espirais, com dominância de pontoações podocarpoides representadas por ooporos (1 ou 2) simples nos campos de cruzamento e parênquima axial, restringe a comparação com os morfogêneros mesozoicos Oguraxylon Nishida e Taxaceoxylon Krausel \& Jain, os quais, porém, diferenciam-se por apresentar pontoações de tipo oculiporo nos campos de cruzamento. Perizemoxylon He \& Zhang, por outro lado, apresenta de 2 a 5 circoporos, levemente areolados (Philippe \& Bamford, 2008).

Embora as características anatômicas detectadas no material não sejam suficientes para uma identificação morfoespecífica, uma afinidade com o padrão abietoide pode ser constatada, levando a definí-lo como xilotipo abietoide, designação morfogenérica que não deve levar à restrita vinculação com grupos atuais, conforme recomendaram Philippe \& Bamford (2008), uma vez que ele ocorre em diferentes grupos de coníferas.

\section{DISCUSSÃO E CONCLUSÕES}

A associação de lenhos aqui analisada apresentou características exclusivamente gimnospérmicas, relacionadas a coníferas, evidenciando-se dominantemente um padrão araucarioide, o que permite inferir, de forma ampla, vinculações com Araucariaceae. O registro do lenho abietoide, embora raro, indica, por outro lado, que na área estudada ocorria pelo menos outra forma de conífera.

A composição da associação paleoflorística registrada na Laje do Coringa é limitada, até o momento, a três grupos vegetais: Gymnospermae, Pteridophyta e Sphenophyta (Medeiros, 2001). Entretanto, para a localidade do Farol de São Marcos, impressões de folhas de Angiospermae foram citadas por Klein \& Ferreira (1979). A comparação dessa associação fóssil do norte Maranhense com a do Araripe (Mohr et al., 2006, 2007; Kunzmann et al., 2004, 2006; Rendon, 2007; Fanton et al., 2006, 2007) do intervalo Aptiano-Albiano, demonstra uma similaridade em nível de grandes grupos, caracterizada pela presença de Araucariaceae em associação com Sphenophyta e Pteridophyta. No norte do continente africano, nos depósitos do Continental Intercalar do Saara, de idade cenomaniana, também há registros de flora com domínio de coníferas, e a fauna de peixes e tetrápodes associada tem notável similaridade com aquela da Formação Alcântara (Medeiros, 2001; Medeiros \& Schultz, 2002). O registro paleoflorístico do Saara é, porém, muito mais diversificado, permitindo inclusive a definição de diferentes zonas de colonização (Lefranc \& Guiraud, 1990).

Por outro lado, dados palinológicos obtidos para a Formação Alcântara no norte do Maranhão registram uma expressiva diversidade tanto de coníferas quanto de angiospermas (Pedrão et al., 1993c; Rossetti et al., 2001b). A discrepância entre os dados palinológicos e os obtidos no presente estudo poderia ser atribuída a diferentes fatores. Deste modo, uma combinação de circunstâncias tafonômicas, que envolveria inicialmente a seleção no transporte e soterramento e, posteriormente, a seleção por resistência, poderia ter criado o viés observado no registro paleoflorístico da Laje do Coringa. Assim, a ocorrência quase exclusiva dos padrões lenhosos atribuíveis a Araucariaceae na amostragem seria consequência de sua distribuição mais próxima aos canais fluviais envolvidos com o transporte e soterramento. A dominância do padrão araucarioide na amostra é coerente com a ocorrência do grão de pólen Araucariacites, previamente reportado, o que é facilmente contextualizado no cenário gondwânico, visto que as araucariáceas eram ampla- mente distribuídas no norte da África e no hemisfério sul, incluindo a região do Araripe, durante o Cretáceo (Lefranc \& Guiraud, 1990; Kunzmann et al., 2006; Bamford, 2004).

Os dados aqui obtidos podem ser comparados a resultados de estudos paleoxilológicos integrados a resultados palinológicos em sequências estratigráficas que gradam desde sedimentos marinhos até parálicos e terrestres, no Cretáceo Superior (Estados Unidos), os quais permitiram inferir que as coníferas eram plantas dominantes em florestas costeiras, tornando-se gradativamente subordinadas em florestas continentais (Baghai, 1996; Wheeler \& Lehman, 2005). As coníferas e as angiospermas dicotiledôneas, nesse contexto, não estariam igualitariamente presentes no mesmo paleoambiente, compondo sucessões distintas. Prévios estudos palinológicos (Pedrão et al., 1993a,b,c) de caráter mais amplo, abordando o Grupo Itapecuru e incluindo a Formação Alcântara, objeto do presente estudo, permitiram inferir que coníferas e angiospermas se desenvolviam em paleoambientes diferenciados no intervalo estudado. Segundo esses dados, enquanto as coníferas desenvolviam-se em paleoambientes costeiros, com influência de águas mixohalinas, as angiospermas concentravam-se no interior, com influência dulcícola.

Os padrões de crescimento ininterrupto, representados pela grande maioria dos espécimes aqui descritos, indicam que as árvores viviam em um ambiente estável onde as requisições mínimas de crescimento da planta estão presentes de maneira constante (tipo “O” de Creber \& Chaloner, 1984). O paleoclima inferido para o norte do Maranhão no meso-Cretáceo (Albiano e Eocenomaniano) é de predominante tendência à aridez (Pedrão et al., 1993a,b,c). No entanto, a grande concentração de lenhos oriundos da Formação Alcântara, em vários pontos da baía de São Marcos, indica a presença de extensos bosques arbóreos litorâneos (Medeiros et al., 2007), o que é coerente com a existência de um amplo estuário na região, possivelmente na forma de um delta (Mesner \& Wooldridge, 1964; Klein \& Ferreira, 1979; Pedrão et al., 1993c), capaz de manter o suprimento de água doce regular ao longo do ano, pelo menos dentro do perímetro recortado pelos canais. Dessa forma, as informações dendrológicas levantadas podem ser contextualizadas dentro do modelo ambiental e do padrão climático assumidos para a região norte do Maranhão em trabalhos previamente realizados: um regime de chuvas torrenciais confinadas a um curto intervalo de tempo, seguido por longo intervalo de estiagem (Medeiros \& Schultz, 2002; Medeiros et al., 2007), em um ambiente estuarino formado por amplos canais que retinham umidade suficiente para manter bosques de coníferas por todo o ano, mas cercado por uma paisagem árida ou semi-árida (Pedrão et al., 1993a,b,c). Dependendo da maior ou menor proximidade de uma determinada planta do suprimento permanente de água, ela seria mais ou menos afetada por eventuais episódios severos de seca. Nesse contexto, as zonas de crescimento observadas em dois espécimes são feições indicadoras de crescimento das plantas em ambientes com disponibilidade suficiente de água (Schweingruber, 1996), mas com ocorrência de fases em que o suprimento aquífero era racionado, talvez ocasionado por secas de verão. Os lenhos que apresentam esses padrões de crescimento parcialmente interrompido podem ter crescido nos limites do estuário ou mais a montante e podem ter sido afetados por episódios de seca esperados para um ambiente de estiagem prolongada, como é assinalado para a região. A geração das fraturas com orientação radial, encontradas em espécimes enquadrados nesse padrão de crescimento parcialmente interrom- 
pido, pode estar relacionada a processos ocorrentes durante a vida da planta, como consequiência de teores insuficientes de água circulante no caule, resultante de episódios de seca (Grabner et al., 2006), por processos gerados por excesso de transpiração e também deficiência de aporte aqǘf́ero desde o sistema radicular (Cherubini et al., 1997) ou por processos de tensão interna do lenho (Schweingruber, 2007). Bolzon et al. (2004) relacionaram estas feições a estágios post mortem em lenhos atuais. As feições morfológicas do lenho comprimido observadas em alguns espécimes (Figura 5) são semelhantes àquelas consequentes de deformação mecânica (Selmeier, 1997), ocorrentes, no caso, antes do processo de sepultamento, ocasionadas na vigência de condições de decomposição anaeróbica em ambiente subaquático. O lenho com padrão abietoide, dado o conjunto de características anatômicas, pode representar coníferas com porte arborescente, talvez aparentadas às Taxaceae atuais, adaptadas a ambientes mais continentais. A ocorrência da Pteridophyta arborescente Paradoxopteris (Mussa et al., 2000) reforça a interpretação de que o domínio era estuarino, incluindo ambiente análogo a manguezais, visto que essas plantas têm sido associadas a tais ecossistemas, colonizando substratos instáveis próximos a corpos d'água (Koeniguer, 1966).

Os resultados coadunam-se com as condições vigentes no cinturão equatorial úmido na área limítrofe com o cinturão Quente e Árido do Norte (Chumakov, 1995; Skelton et al., 2003). As reconstituições de paleolatitudes situam a linha do equador no norte da Venezuela, extremo norte da América do Sul, no início no Cretáceo Superior (e.g. Scotese, 2003; Blakey, 2004). Com base nestas reconstituições, a posição latitudinal do norte Maranhense (atualmente $2^{\circ} 30^{\prime} \mathrm{S}$ na altura da Ilha do Cajual) no início do Cenomaniano estaria cerca de $9^{\circ}$ mais ao sul.

Embora a atividade cambial contínua em plantas desenvolvidas no cinturão equatorial seja importante na determinação da ausência de ciclos de crescimento, mesmo nessas condições as plantas submetidas a microclimas regionais não têm, muitas vezes, crescimento contínuo ao longo do ciclo anual (Fahn, 1990; Kramer \& Kozlowski, 1979).

\section{AGRADECIMENTOS}

Agradecemos os alunos do curso de graduação em Ciências Biológicas da UFMA pelo valioso auxílio nos trabalhos de campo e à UFMA, UFRGS e CAPES pelo suporte financeiro.

\section{REFERÊNCIAS}

Alvin, K.L. 1982. Cheirolepidiaceae: biology, structure and paleoecology. Review of Palaeobotany and Palynology, 37(12):71-98.

Alvin, K.L.; Fraser, C.J. \& Spicer, R.A. 1981. Anatomy and palaeoecology of Pseudofrenelopsis and associated conifers in the English Wealden. Paleontology, 24:759-778.

Aranha, L.G.F.; Lima, H.P.; Souza, J.M.P. \& Makino, R.K. 1990. Origem e evolução das Bacias de Bragança-Viseu, São Luís e Ilha Nova. In: G.P. Raja-Gabaglia \& E.J. Milani (eds.) Origem e evolução de bacias sedimentares, PETROBRAS, p. 221-232.

Axsmith, B.J. 2006. The vegetative structure of a Lower Cretaceous conifer from Arkansas: further implications for morphospecies concepts in the Cheirolepidiaceae. Cretaceous Research, 27(3):309-317.

Baghai, N.L. 1996. An analysis of palynomorphs from Upper Cretaceous sedimentary rocks with emphasis on the Aguja Formation, Big Bend National Park, Brewster County, Texas. University of Texas, Ph. D. dissertation, $495 \mathrm{p}$.
Bamford, M.K. 2004. Diversity of the woody vegetation of Gondwanan Southern Africa. Gondwana Research, 7(1):153164. doi:10.1016/S1342-937X(05)70314-2

Blakey, R. 2004. Paleogeography through geologic time. Department of Geology, Northern Arizona University. Available at http:// jan.ucc.nau.edu/ rcb7/global_history.html; accessed on 21/09/2010.

Bolzon, R.T.; Azevedo, I. \& Machado, L.G. 2004. Registro da atividade de organismos em um caule do Permiano do Rio Grande do Sul, Brasil. Arquivos do Museu Nacional, 62(4):513-518.

Boureau, E. 1956. Anatomie végétale. Paris, Presses Universitaires de France, $524 \mathrm{p}$.

Campbell, D.F.; Almeida, L.A. \& Silva, S. O. 1949. Relatório preliminar sobre a geologia da bacia do Maranhão. Rio de Janeiro, Conselho Nacional de Petróleo, 60 p. (Boletim 1).

Cherubini P.; Schweingruber F.H. \& Foster, T. 1997. Morphology and ecological significance of intra-annual radial cracks in living conifers. Trees-structure and function, 11(4):216-222.

Chumakov, N.M. 1995. Climatic zones in the middle of the Cretaceous period. Stratigraphy and Geological Correlation, 3:3-14.

Corrêa Martins, F.J. 1997. A Laje do Coringa: um "bone-bed" da Formação Itapecuru (Cretáceo Superior da bacia de São Luís-MA). Anais da Academia Brasileira de Ciências, 69(3):436-437.

Creber, G.T. \& Chaloner, W.G. 1984. Influence of environmental factors on the wood structure of living and fossil trees. The Botanical Review, 50(4):357-448.

Creber, G.T. \& Francis, J.E. 1999. Tree ring analysis: palaeodendrochronology. In: T. Jones \& N. Rowe (eds.) Fossil plants and spores: modern techniques. Geological Society, p. 245-250.

Elias, F.A.; Bertini, R.J. \& Medeiros, M.A. 2007. Pterosaur teeth from the Laje do Coringa, middle Cretaceous, São Luís-Grajaú Basin, Maranhão, Northern-Northeastern Brazil. Revista Brasileira de Geociências, 37(4):668-676.

Fahn, A. 1990. Plant Anatomy. $4^{\mathrm{a}}$ ed. Oxford, Pergamon Press, 600 p.

Fanton, J.C.M.; Ricardi-Branco, F.; Dilcher, D. \& Bernardes-de-Oliveira, M. 2006. Iara iguassu, a new taxon of aquatic angiosperm from the Crato palaeoflora (Lower Cretaceous, Santana Formation, Araripe Basin, Northeastern Brazil). Geociências, 25(2):211-216.

Fanton, J.C.M.; Ricardi-Branco, F.; Dilcher, D.L.; Campos, A.C. de A. \& Tavares, S.A.S. 2007. Macrofóssil inédito de Caytoniales na Formação Crato, Cretáceo Inferior, bacia do Araripe, NE, Brasil: estudo preliminar. In: I.S. Carvalho; R.C.T. Cassab; C. Schwanke; M.A. Carvalho; A.C.S. Fernandes; M.A.C. Rodrigues; M.S.S. Carvalho; M. Arai \& M.E.Q. Oliveira (eds.) Paleontologia: Cenários de vida, Interciência, v. 1, p. 177-188.

Góes, A. M. \& Rossetti, D. F. 2001. Gênese da bacia de São LuísGrajaú, Meio-Norte do Brasil. In: D.F. Rossetti; A.M. Góes \& W. Truckenbrodt (eds.) O Cretáceo na bacia de São Luis-Grajaú, Museu Paraense Emilio Goeldi, p. 15-29.

Grabner, M.; Cherubini, P.; Rozenberg, P. \& Hannrup, B. 2006. Summer drought and low earlywood density induce intra-annual radial cracks in conifers. Scandinavian Journal of Forest Research, 21:151-157. doi: $10.1080 / 02827580600642100$

Gradstein, F.M. \& Ogg, J.G. 1996. A Phanerozoic Time Scale. Episodes, 19(1-2):3-6.

Holz, M. 2003. Sequence stratigraphy as a tool for vertebrate taphonomy. An example from a Late Cretaceous dinosaur taphocoenosis from São Luís Basin, Northern Brazil. In: LATIN AMERICAN CONGRESS SEDIMENTOLOGY, 3, 2003. Abstracts, Belém, MPEG, p. 213-214.

Johnson, K.R. 1996. Description of seven common fossil leaf species from the Hell Creek Formation (Upper Cretaceous-Upper Maastrichtian), North Dakota, South Dakota, and Montana. Proceedings of the Denver Museum of Natural History, 3(12):1-48.

Klein, V.C. \& Ferreira, C.S. 1979. Paleontologia e estratigrafia de uma fácies estuarina da Formação Itapecuru, Estado do 
Maranhão. Anais da Academia Brasileira de Ciências, 51(3):523-533.

Koeniguer, J.C. 1966. Étude paléophytogéographyque du continental intercalaire de l'Afrique Nord-Équatoriale. B - Sur de nouveaux échantillons du genre Paradoxopteris. Mémoires de la Societé Geólogique de France, 105:100-112.

Kunzmann, L.; Mohr, B.A.R. \& Bernardes-de-Oliveira, M.E.C. 2004. Gymnosperms from the Lower Cretaceous Crato Formation (Brazil) I. Araucariaceae and Lindleycladus (incertae sedis). Mitteilungen aus dem Museum für Naturkunde BerlinGeowissenschaftliche Reihe, 7:155-174.

Kunzmann, L.; Mohr, B.A.R.; Bernardes-de-Oliveira, M.E.C. \& Wilde, V. 2006. Gymnosperms from the Early Cretaceous Crato Formation (Brazil): II. Cheirolepidiaceae. Fossil Record, 9(2):213-225.

Kramer, P.J. \& Kozlowski, T.T. 1979. Physiology of woody plants. New York, New York Academic Press, 811 p.

Lauverjat, J. \& Pons, D. 1978. Le gisement Sénonien d'Esgueira (Portugal): Stratigraphie et flore fossile. CONGRÈS NATIONAL DES SOCIÉTÉS SAVANTES, 103, 1978. Comptes Rendues, Nancy, v. 2, p. 119-137.

Lefranc, J.P. \& Guiraud, R. 1990. The Continental Intercalaire of Northwestern Sahara and its equivalents in the neighbouring regions. Journal of African Earth Sciences, 10(1-2):27-77.

Medeiros, M.A. 2001. A Laje do Coringa (Ilha do Cajual, bacia de São Luís, baía de São Marcos, MA). Conteúdo fossilífero, bioestratinomia, diagênese e implicações na paleobiogeografia do meso-Cretáceo do nordeste brasileiro. Programa de Pós-Graduação em Geociências, Universidade Federal do Rio Grande do Sul, Tese de Doutorado, $137 \mathrm{p}$.

Medeiros, M.A. \& Schultz, C.L. 2002. A fauna dinossauriana da Laje do Coringa, Cretáceo médio do Nordeste do Brasil. Arquivos do Museu Nacional, 60(3):155-162.

Medeiros, M.A. \& Schultz, C.L. 2004. Rayososaurus (Sauropoda, Diplodocoidea) no Meso-Cretáceo do norte-nordeste brasileiro. Revista Brasileira de Paleontologia, 7(2):275-279.

Medeiros, M.A.; Freire, P.C.; Pereira, A.A.; Santos, R.A.B.; Lindoso, R.M.; Coêlho, A.F. do A.; Passos, E.B. \& Junior, E.S. 2007. Another African dinosaur recorded in the Eocenomanian of Brazil and a revision on the paleofauna of the Laje do Coringa site. In: I.S. Carvalho; R.C.T. Cassab; C. Schwanke; M.A. Carvalho; A.C.S. Fernandes; M.A.C. Rodrigues; M.S.S. Carvalho; M. Arai \& M.E.Q. Oliveira (eds.) Paleontologia: Cenários de Vida, Interciência, v. 1, p. $413-423$.

Mesner, J.C. \& Wooldridge, P. 1964. Estratigrafia das bacias paleozóicas e cretácea do Maranhão. Boletim Técnico da Petrobras, 7(2):137-164.

Mohr, B.A.R.; Bernardes-de-Oliveira, M.E.C.; Barale, G. \& Ouaja, M. 2006. Palaeogeographic distribution and ecology of Klitzschophyllites, an early Cretaceous angiosperm, in southern Laurasia and northern Gondwana. Cretaceous Research, 27(3):464-472.

Mohr, B.A.R.; Bernardes-de-Oliveira, M.E.C. \& Loveridge, R.F. 2007. The macrophyte flora of the Crato Formation. In: D.M. Martill; G. Bechly \& R.F. Loveridge (eds.) The Crato fossil beds of Brazil: window into an ancient world, Cambridge University Press, p. 537-565.

Mussa, D.; Carvalho, I.S.; Martins, F.J.C. \& Zuccoloto, M.E. 2000. Paradoxopteris Hirmer 1927, o caule de Weichselia Stiehler, 1857 presente no Cretáceo da bacia de São Luís, Estado do Maranhão, Brasil. Revista Universidade de Guarulhos, Geociências, 5(6):60-70.

Page, V.M. 1979. Dicotyledoneous wood from the Upper Cretaceous of Central Califórnia. Journal of the Arnold Arboretum, 60:323-349.

Page,V.M. 1980. Dicotyledoneous wood from the Upper Cretaceous of Central Califórnia II. Journal of the Arnold Arboretum, 61:723 -748.

Page,V.M. 1981. Dicotyledoneous wood from the Upper Cretaceous of Central Califórnia III. Journal of the Arnold Arboretum, 62:437-455.

Pedrão, E.; Arai, M.; Barrilari, I.M.R. \& Carvalho, I.S. 1993a. Análise palinológica de uma amostra de superfície de Querru (Formação Itapecuru), município de Itapecuru-Mirim (MA). In: CONGRES-
SO BRASILEIRO DE PALEONTOLOGIA, 13,1993. Resumos, São Leopoldo, UNISINOS/CPRM, p. 175.

Pedrão, E.; Arai, M.; Carvalho, I.S. \& Ferreira, C.S. 1993b. Palinomorfos de sedimentos albianos (Formação Itapecuru) da bacia do Parnaíba. Rio de Janeiro, PETROBRAS, CENPES, 13 p. (Relatório Técnico).

Pedrão, E.; Arai, M.; Carvalho, I.S. \& Santos, M.H.B. 1993c. Palinomorfos da Formação Itapecuru - análise palinológica de uma amostra de superfície da Ponta do Farol, São Luís, MA. Rio de Janeiro, PETROBRAS, CENPES, 10 p. (Relatório Técnico).

Pereira, A.A. \& Medeiros, M.A. 2008. A new Sclerorhynchiform (Elasmobranchii) from the middle Cretaceous of Brazil. Revista Brasileira de Paleontologia, 11(3):207-212.

Philippe, M. 1993. Nomenclature générique des trachéidoxyles mésozoiques à champs araucarioides. Taxon, 42:74-80.

Philippe, M. \& Bamford, M.K. 2008. A key to morphogenera used for Mesozoic conifer-like woods. Review of Palaeobotany and Palynology, 148(2-4):184-207.

Rendon, P.A.S. 2007. Gimnospermas eocretáceas da Formação Crato, bacia do Araripe, Nordeste do Brasil. Programa de Pós-Graduação em Geologia Sedimentar, Universidade de São Paulo, Dissertação de Mestrado, 108 p.

Rossetti, D.F. 1997. Internal architecture of mixed tide- and stormdominated deposits: an example from the Alcântara Formation, northern Brazil. Sedimentary Geology, 114(1-4):163-188.

Rossetti, D. F. 2001. Arquitetura deposicional da bacia de São LuísGrajaú. In: D.F. Rossetti; A.M. Góes \& W. Truckenbrodt (eds.) $O$ Cretáceo na bacia de São Luis-Grajaú, Museu Paraense Emilio Goeldi, p. 31-46.

Rossetti, D.F. \& Truckenbrodt, W. 1997. Revisão estratigráfica para os depósitos do Albiano-Terciário Inferior (?) na bacia de São Luís, Maranhão. Boletim do Museu Paraense Emílio Goeldi (Série Ciências da Terra), 9:29-41.

Rossetti, D. F.; Góes, A. M. \& Truckenbrodt, W (eds.) 2001a. O Cretáceo na bacia de São Luís-Grajaú. Belém, Museu Paraense Emilio Goeldi, 264 p.

Rossetti, D. F.; Góes, A. M. \& Arai, M. 2001b. A passagem AptianoAlbiano na bacia do Grajaú, MA. In: D.F. Rossetti; A.M. Góes \& W. Truckenbrodt (eds.) O Cretáceo na bacia de São Luis-Grajaú, Museu Paraense Emilio Goeldi, p. 101-117.

Schopf, J.M. 1975. Modes of fossil preservation. Review of Palaeobotany and Palynology, 20(1-2):27-53.

Schweingruber, F.H. 1996. Tree rings and environment dendroecology. Stuttgart, Swiss Federal Institute for Forest, Snow and Landscape Research, 609 p.

Schweingruber, F.H. 2007. Wood structure and environment. Berlin, Springer, $279 \mathrm{p}$.

Scotese, C.R. 2003. Paleo Atlas Project. Available at www.scotese.com/ images/top_htm; accessed on 22/09/2010.

Selmeier, A. 1997. Fossil wood from Allan Hills and Litell Rocks, Victoria Land, Antarctica. Extract Mitteilungen der Bayerischen Staatssammlung für Paläontologie und Historische Geologie, 37:95-118.

Skelton, P.W.; Spicer, R.A.; Kelley, S.P. \& Gilmour, I. 2003. The Cretaceous World. Cambridge, Cambridge University Press, $360 \mathrm{p}$.

Smit, J. 1999. The global stratigraphy of the Cretaceous-Tertiary boundary impact ejecta. Annual Review of Earth and Planetary Sciences, 27:75-113.

Wheeler,E.A. \& Lehman, T.M. 2005. Upper Cretaceous-Paleocene conifer woods from Big Bend National Park, Texas. Palaeogeography, Palaeoclimatology, Palaeocology, 226(3-4):233-258.

Wheeler, E.A. \& Michalski, T.M. 2003. Paleocene and early Eocene woods of the Denver Basin, Colorado. Rocky Mountain Geology, 38(1):29-43.

Received in May, 2010; accepted in November, 2010. 